\title{
OPEN PARTIAL NEPHRECTOMY FOR SMALL RENAL TUMOURS: TECHNICAL AND ONCOLOGICAL OUTCOMES
}

\author{
Qamar Zia, Mudassar Sajjad*, Muhammad Akmal, Faran Kiyani**, Muhammad Nawaz**, Sohail Razzaq ${ }^{* * *}$ \\ Combined Military Hospital Lahore/National University of Medical Sciences (NUMS) Pakistan, *Combined Military Hospital Malir/National \\ University of Medical Sciences (NUMS) Pakistan, ${ }^{* *}$ Armed Forces Institute of Urology/National University of Medical Sciences (NUMS) \\ Pakistan, ${ }^{* * *}$ Combined Military Hospital Sialkot/National University of Medical Sciences (NUMS) Pakistan
}

\begin{abstract}
Objective: To assess the safety and oncological outcomes of Open Partial Nephrectomy in management of small renal tumours.

Study Design: Case series.

Place and Duration of Study: Armed Forces Institute of Urology, Rawalpindi, from Jan 2015 to Dec 2018.

Methodology: We prospectively studied 61 patients with renal tumours either observed on computerized tomography (CT) scan or magnetic resonance imaging (MRI) having size $\leq 7 \mathrm{~cm}$ and underwent open partial nephrectomy. The collected data included demographics, dimension of tumour, indication for surgery, cold ischemia time, hospital stay, complications and histopathological finding including involvement of margins. Patients were followed up for atleast 2 years.

Results: Among 61, 39 patients were male and 22 females. The age of patients ranged from 20-72 years. Mean cold ischaemia time was $24.7 \pm 6.37$ minutes. Except for 2 patients with Von Hippel-Lindau (VHL) disease, all other patients had solitary renal growth. Nine $(14.75 \%)$ patients had solitary kidney. The mean of maximum dimension of tumours was $3.84 \pm 1.38 \mathrm{~cm}$ and mean hospital stay was $3.18 \pm 2.19$ days. Histopathological results showed 34 tumours to be conventional renal cell carcinoma (RCC) $(55.73 \%)$ followed by 12 papillary renal cell carcinoma $(19.67 \%)$. Two $(3.27 \%)$ patients had positive surgical margin who were operated for $>5 \mathrm{~cm}$ tumours and later managed expectantly. Twenty one patients had Grade I and II complications while 2 patients were stented post operatively for urine leak. At 2 years follow up there was no recurrence of tumour in any of the patient operated. Conclusion: Open partial nephrectomy was found technically and oncologically safe procedure in T1 tumours and negative margins can be achieved by macroscopic clearance by the experienced operating surgeon.
\end{abstract}

Keywords: Cold ischemia time, Humans. Kidney cancer, Kidney neoplasm, Margins of excision. Nephrectomy, Renal neoplasm, Warm ischemia time.

This is an Open Access article distributed under the terms of the Creative Commons Attribution License (http://creativecommons.org/licenses/by/4.0), which permits unrestricted use, distribution, and reproduction in any medium, provided the original work is properly cited.

\section{INTRODUCTION}

Not only modern and readily available investigations like ultrasound and computed tomography can detect renal tumours much earlier and it has led to their prompt treatment ${ }^{1}$. Among various treatment options, radical nephrectomy $(\mathrm{RN})$ is considered the gold standard treatment for the localized renal tumours as it provides outstanding and complete cure of disease with minimal recurrence and improved overall survi$\mathrm{val}^{2}$. However, among other options for surgical treatments for localized tumours is open Partial Nephrectomy (PN). It was carried out by Czerny

Correspondence: Dr Qamar Zia, Consultant Urologist, Combined Military Hospital, Lahore Pakistan

Received: 21 Oct 2019; revised received: 18 Dec 2019; accepted: 20 Dec 2019 in 1887 and Vermooten in 1950 explained its detailed indications in renal malignancies. With advanced surgical techniques and well understood anatomy open $\mathrm{PN}$ is now considered the 'gold standard' treatment for small kidney tumours ${ }^{3}$.

As per tumor, nodes and metastases (TNM) classification of 1997, T1 kidney tumours are further classified as T1a $(\leq 4 \mathrm{~cm})$ and T1b $(4-7 \mathrm{~cm})^{4}$. The recent European Association of Urolog (EAU) guidelines for the management of renal masses emphasize PN for all anatomically amenable T1 renal tumours 5 . It saves the renal parenchyma and in turn better renal function is linked with less cardiovascular mishaps and improved overall survival compared to similar patients 
who undergo $\mathrm{RN} 6,7$. This preservation of renal function is the main purpose of PN. The Published data have shown that oncological outcomes of open PN are comparable to those of $\mathrm{RN}$ for small renal tumours ${ }^{8}$.

The goals of PN other than preservation of normal renal parenchyma is meticulous cancer control with negative surgical margins and no local recurrence in the follow-up ${ }^{9}$. It's been debated that PN sometime can jeopardize the oncological outcome especially when resected margins are reported involved on the final histopathological examination. However, there is another school of thought and the published literature supports the opposite view point ${ }^{10-12}$, and advocate the prevention of sequel of subsequent chronic kidney disease by saving precious normal renal parenchyma ${ }^{13}$.

In Pakistan there have been very few studies published upon PN and its relationship to the resected margins. We were able to find only one study with six months follow-up based upon a single centre experience ${ }^{1}$. Our research paper evaluated the feasibility of open PN technique in the management of small renal tumours in terms of safety, achieving safe resection margins and correlation of positive margins with local recurrence of disease.

\section{METHODOLOGY}

Approval from Institutional review board and ethics committee was sought (IRB-105-2172014). This study was conducted at Armed Forces institute of Urology, Rawalpindi, Pakistan, from January 2015 to December 2018.

The criteria for the inclusion was patients, who presented to us with renal tumours observed on CT scan and MRI of size $\leq 7 \mathrm{~cm}$, while less than 18-year-old patients and in whom open PN were converted into Radical Nephrectomies were excluded. Therefore 61 patients who successfully underwent open PN were selected.

The procedure of the open PN remained the same as mostly the selected group was operated or supervised by asingle surgeon. Informed writ- ten consent was obtained. All patients were operated under general anaesthesia through a supra $11 / 12^{\text {th }}$ flank approach. Control of renal artery was taken by rubber sling around it. Kidney was freed off the surrounding para-renal fat, while fat over the tumour was not disturbed. The dissection plane was marked over kidney capsule with minimum of $1 \mathrm{~cm}$ safe margin and kidney was placed in the bag and filled with ice slush. After 10 minutes, renal artery was clamped using a bulldog clamp. Electrocautery was used to deepen the scored resection line, and the tumor was excised with adequate margin of normal renal parenchyma with sharp and blunt dissection using a tenotomy scissors and Penfield neurological spatula. Parenchymal vessels were tied with PDS 5/0. The kidney was repaired primarily with PDS 4/0 using the renal capsule before releasing the renal artery clamp. For large tumours complete hilar clamps were also used. Drain was placed and wound was closed with improvised pain buster system in place for prompt control of the pain post-operatively.

The data was recorded for the name, gender, age, date, side, position, indication and presentation for the open PN. In addition, dimension of the growth, histopathological finding (diagnosis \& involvement of margins), hospital stay in days and post-operative complications (ClavienDendo-system) were noted. The follow-up period was kept to 2 years. All the data was entered in a specially designed proforma and statistical analysis was performed by using Predictive Analytics Software PASW statistics 18 (formerly SPSS Statistics). Mean \pm SD was calculated for quantitative variables. Frequency and percentage were calculated for qualitative variables.

\section{RESULTS}

Among 61 patients, there were 39 (63.9\%) male and $22(36.1 \%)$ female patients. The age of patients ranged from 20-72 years. The main presentation was incidentaloma found in 42 (69\%) patients followed by haematuria 12 (19\%) (table-I). Thirty four surgeries were carried out on right and 27 on left kidney. Mean cold ischaemia 
time was $24.7 \pm 6.37$ mins. Two patients with VHL disease had bilateral open PN. Solitary kid-

Table-I: Mode of presentation.

\begin{tabular}{l|c}
\hline Mode & n (\%) \\
\hline Incidental & $42(69)$ \\
\hline Haematuria & $12(19)$ \\
\hline Loin Pain & $7(12)$ \\
\hline
\end{tabular}

Table-II: Final histology result.

\begin{tabular}{l|c}
\hline Pathology & n (\%) \\
\hline Malignant (RCC-Clear cell) & $34(55.7)$ \\
\hline Malignant (RCC-Papillary) & $12(19.7)$ \\
\hline Malignant (RCC-Chromophobe) & $5(8.2)$ \\
\hline Benign (Oncocytoma) & $8(13.1)$ \\
\hline Benign (Tuberculous infection) & $1(1.6)$ \\
\hline Benign (XGP) & $1(1.6)$ \\
\hline
\end{tabular}

ney was operated in $9(14.75 \%)$ patients. The mean of maximum dimension of tumour was 3.84 $\pm 1.38 \mathrm{~cm}$ and mean hospital stay was $3.18 \pm 2.19$ days (fig-1).

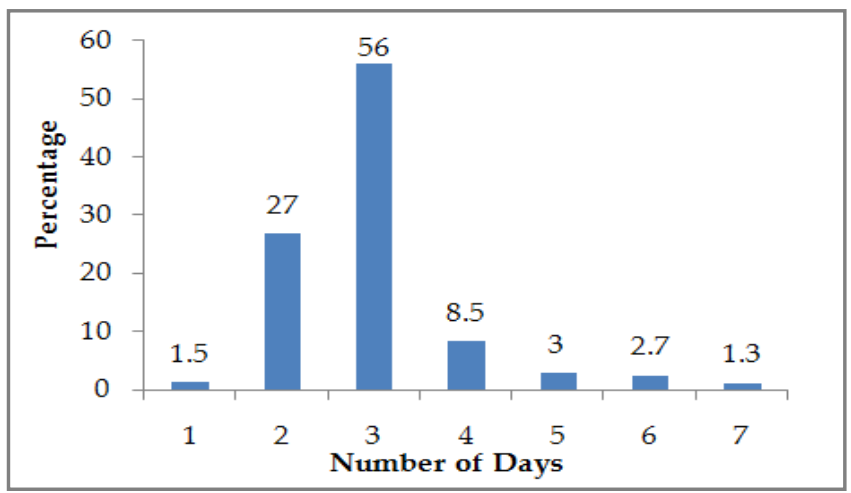

Figure-1: Post-operative hospital stay in days.

Histopathology results showed 34 tumours to be conventional RCCs (55.73\%) followed by 12

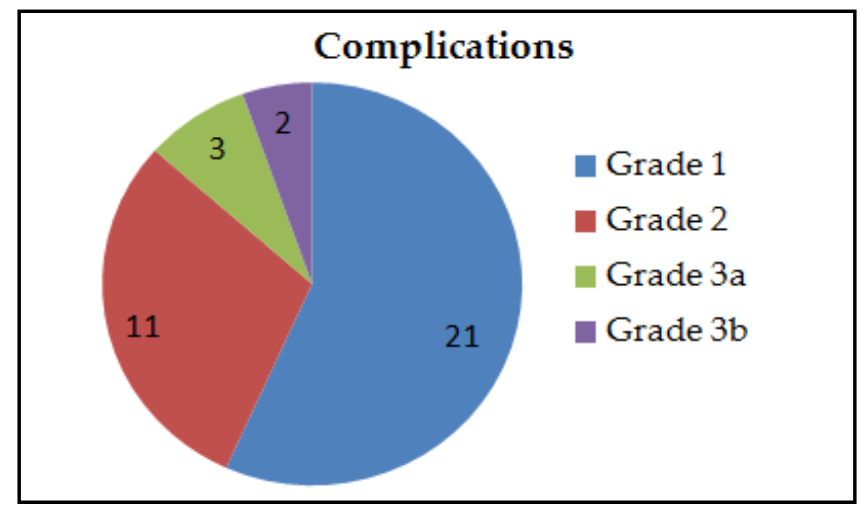

Figure-2: Post OP complication (clavien-dindo classification). papillary RCCs (19.67\%) (table-II). Two patients had positive surgical margin who were operated for $>5 \mathrm{~cm}$ tumours and later on managed by the expectant treatment.

Twenty one patients had Grade I and II complications while 2 patients were stented post operatively for urine leak (fig-2). At 2 years follow up there was no recurrence of tumour in any of the patient operated.

\section{DISCUSSION}

The malignant renal neoplasms constitute the primary and the secondary tumours of the kidney and approximately $85 \%$ of primary malignant renal tumours develop in the renal parenchyma and nearly all of these are renal cell carcinomas (RCC). From 2006 to 2015, its rate has increased by about $1 \%$ per year ${ }^{14}$. There has been a trend of decline in the developed countries especially European countries but overall globally a rise is noted in the prevalence of $\mathrm{RCC}^{15}$.

Murtaza et al 16 , Carried out a study on the renal neoplasm in our institute from 2008 to 2010 which showed that the malignant renal tumours were mostly seen in the $6^{\text {th }}$ and $7^{\text {th }}$ decade $(44.6 \%)$ and the Male to Female ratio was 2.1:1. This study was conducted on the patients who were undergoing RN. We found almost the same gender distribution in our study. However, we have seen difference in the age of presentation as our patients were mostly in their $4^{\text {th }}$ and $5^{\text {th }}$ decade (Mean 43.84). Rahim et al17. reported mean age of presentation 46.51 years of same population who underwent open PN. The early age at presentation of small renal tumours can be explained by the fact that these are mostly incidentalomas and can be picked up at early age and stage of disease. Murtaza et al in the same study mentioned that majority of tumours were unifocal (96.7\%) and only $3(3.2 \%)$ cases showed multifocality and in this study we found the similar presentation too.

We saw conventional clear cell RCC (ccRCC) as the commonest (55.73\%) tumour followed by papillary RCC (19.67\%), while Murtaza et al, also reported ccRCC as the commonest followed by 
transitional cell carcinoma (7.6\%). Rahim et al. Who studied on partial nephrectomy patients also found clear cell RCC to be the commonest (58.3\%) among the malignant tumours followed by papillary RCC (41.67\%). Moreover, he reported $40 \%$ of renal tumours as benign while in this study benign tumours were $16.3 \%$.

We found that $69 \%$ of renal tumours were picked up incidentally followed by haematuria as presenting symptom. A prospective observational study carried out by Ghaffar et al18. Over 5 years (1999-2004) reported pain (60\%) as the main complaint rather than incidental or haematuria. Whereas Rahim et al. reported most patients $(65 \%)$ with small renal tumours are picked up incidentally followed by renal pain $(20 \%)$. This difference of presentations in three studies including ours needs to be further verified and researched before reaching any conclusion regarding the mode of presentation.

Excellent haemostasis is considered of utmost importance for carrying out $\mathrm{PN}$ as it allows the surgeon to optimally visualize resection margins as well as depth of resection. This factor is critical to achieve a negative margin. It is postulated that a warm ischaemia time of $<30$ could allow complete reversal of renal function ${ }^{19}$. Hypothermia is necessary in patients when the warm ischaemia time is expected to exceed $30 \mathrm{~min}^{20}$, as it induces short-term suspension of renal metabolism and minimizes post ischaemic renal injury. Furthermore, upon achieving renal parenchymal temperature of $20^{\circ} \mathrm{C}$, the kidney can tolerate up to 3-hours of ischaemic time without permanent renal injury ${ }^{21}$. In all our patients, kidney was cooled with ice slush to achieve maximum nephron sparing.

In our institution we donot routinely perform frozen section and ensure the safety of margins macroscopically. There are enough studies published internationally which emphasize the unreliability of frozen section in respect to resection margins and leading into mixed results ${ }^{22}$. We found that 2 patients had positive margins on final histopathology report, but after 2 years of follow up based on risk stratification none of those patients had shown recurrence of disease.

Marszelek et $a l^{23}$, concluded that margins were involved in up to $7 \%$ of case safter Open PN. They refuted the idea that frozen section can be of any major clinical significance and emphasized upon the technique and macroscopic assessment of surgeon to be superior in getting better results. Research carried by Sterious et al ${ }^{24}$. Resulted in getting positive margins in $11 \%$ of patients with no frozen section in comparison with $4.5 \%$ of patients who had a frozen section $(p=0.01)$; however, this finding became statistically insignificant when selecting for patients with a malignant tumour on final pathology. Ani et al 25 , in their population-based research found quite few numbers of positive surgical margins but it did not affect the outcome on 5-year disease-specific and overall survival rates. A positive surgical margin may not reflect the residual tumour and most of the times it is destroyed by the coagulation of the tumour bed.

PN for renal tumours is a very complex procedure. At present it is being performed at very few centers in Pakistan. Late presentation renders very few tumours amenable to PN.

\section{CONCLUSION}

Open Partial nephrectomy was found technically and oncologically safe procedure in T1 tumours and safe margins can be achieved by macroscopic resection. It should be attempted in all anatomically amenable T1 tumours.

\section{CONFLICT OF INTEREST}

This study has no conflict of interest to be declared by any author.

\section{REFERENCES}

1. Olson MC, Abel EJ, Mankowski Gettle L. Contrast-Enhanced Ultrasound in Renal Imaging and Intervention. Curr Urol Rep 2019; 20(11): 73-75.

2. Long CJ, Canter DJ, Kutikov A, Li T, Simhan J, Smaldone M. Partial nephrectomy for renal masses $\geq 7 \mathrm{~cm}$ : technical, oncological and functional outcomes. BJU Int 2012; 109(10): 1450-56.

3. Hu M, Guan C, Xu H, Gu M, Fang W, Yang X. Comparison of 3dimensional laparoscopy and conventional laparoscopy in the treatment of complex renal tumor with partial nephrectomy: A propensity score-matching analysis. Med (Baltimore) 2019; 98(40): 174-85. 
4. Lee H, Song BD, Byun SS, Lee SE, Hong SK. Impact of warm ischaemia time on postoperative renal function after partial nephrectomy for clinical T1 renal cell carcinoma: a propensity score-matched study. BJU Int 2018; 121(1): 46-52.

5. Nguyen CT, Campbell SC. Staging of renal cell carcinoma: past, present, and future. Clin Genitourin Cancer 2006; 5(3): 190-97.

6. Tran MGB, Aben KKH, Werkhoven E, Neves JB, Fowler S, Sullivan $\mathrm{M}$, et al. Guideline adherence for the surgical treatment of T1 renal tumours correlates with hospital volume: an analysis from the British Association of Urological Surgeons Nephrectomy Audit. BJU Int 2019; 201(9): 1623-25.

7. Huang WC, Elkin EB, Levey AS, Jang TL, Russo P. Open Partial nephrectomy versus radical nephrectomy in patients with small renal tumors - is there a difference in mortality and cardiovascular outcomes. J Urol 2009; 181(3): 55-61.

8. Patard JJ, Shvarts O, Lam JS, Pantuck AJ, Kim HL. Safety and efficacy of partial nephrectomy for all $\mathrm{T} 1$ tumors based on an international multicenter experience. J Urol 2004; 171(1): 2181-85.

9. Sanchez A, Feldman AS, Hakimi AA. Current Management of Small Renal Masses, Including Patient Selection, Renal Tumor Biopsy, Active Surveillance, and Thermal Ablation. J Clin Oncol 2018; 36(36): 3591-00.

10. Ellis RJ. Chronic kidney disease after nephrectomy: a clinicallysignificant entity. Transl Androl Urol 2019; 8(2): 166-74.

11. Rahim W, Khan MA, Iqbal N, Shohab D, Hasan A, Khan HA, et al. Partial Nephrectomy in Adults - A Single-Centre Experience. J Coll Physicians Surg Pak 2018; 28(3): 250-51.

12. Badri AV, Waingankar N, Edwards K, Kutikov A, Parsons RB, Chen DY, et al. Non-contrast imaging characteristics of papillary renal cell carcinoma: implications for diagnosis and subtyping. Can J Urol 2019; 26(5): 9916-21.

13. Murtaza B, Mahmood A, Akmal M, Ahmad H, Niaz WA, Khadim MT. Pattern of Malignant Renal Tumours using 2004 WHO classification of renal tumours on Radical Nephrectomy. J Ayub Med Coll Abbottabad 2011; 23(3): 145-49.

14. Ghaffar F, Sajid M, Anwar K. Transperitoneal approach for radical nephrectomy: five years experience at Pakistan Institute of Medical Sciences, Islamabad, Pakistan. J Ayub Med Coll
Abbottabad 2007; 19(1): 15-18.

15. Wu J, Suk-Ouichai C, Dong W, Zhang Z. Vascularized Parenchymal Mass Preserved with Partial Nephrectomy: Functional Impact and Predictive Factors. Eur Urol Oncol 2019; 2(1): 97-03.

16. Ramani AP, Ryndin I, Lynch AC, Veetil RT. Current concepts in achieving renal hypothermia during laparoscopic partial nephrectomy. BJU Int 2006; 97(2): 342-44.

17. Eroglu M, Unsal A, Bakirtas H, Tekdogan U, Ataoglu O, Balbay MD. Routine frozen-section biopsy from the surgical bed should be performed during nephron-sparing surgery for renal cell carcinoma. Scand J Urol Nephrol 2005; 39(3): 222-25.

18. Marszalek M, Carini M, Chlosta P, Jeschke K, Kirkali Z, Knuchel $\mathrm{R}$, et al. Positive surgical margins after nephron-sparing surgery. Eur Urol 2012; 61(4): 757-63.

19. Gordetsky J, Gorin MA, Canner J, Ball MW, Pierorazio PM, Allaf $\mathrm{ME}$, et al. Frozen section during partial nephrectomy: does it predict positive margins. BJU Int 2015; 116(6): 868-72.

20. Ani I, Finelli A, Alibhai SM, Timilshina N, Fleshner N, Abouassaly $\mathrm{R}$, et al. Prevalence and impact on survival of positive surgical margins in partial nephrectomy for renal cell carcinoma: A population-based study. BJU Int 2013; 111(2): 300-05.

21. Ramani AP, Ryndin I, Lynch AC, Veetil RT. Current concepts in achieving renal hypothermia during laparoscopic partial nephrectomy. BJU Int 2006; 97(2): 342-44.

22. Eroglu M, Unsal A, Bakirtas H, Tekdogan U, Ataoglu O, Balbay MD. Routine frozen-section biopsy from the surgical bed should be performed during nephron-sparing surgery for renal cell carcinoma. Scand J Urol Nephrol 2005; 39(3): 222-25.

23. Marszalek M, Carini M, Chlosta P, Jeschke K, Kirkali Z, Knuchel $\mathrm{R}$, et al. Positive surgical margins after nephron-sparing surgery. Eur Urol 2012; 61(4): 757-63.

24. Gordetsky J, Gorin MA, Canner J, Ball MW, Pierorazio PM, Allaf $\mathrm{ME}$, et al. Frozen section during partial nephrectomy: does it predict positive margins. BJU Int 2015; 116(6): 868-72.

25. Ani I, Finelli A, Alibhai SM, Timilshina N, Fleshner N, Abouassaly R, et al. Prevalence and impact on survival of positive surgical margins in partial nephrectomy for renal cell carcinoma: A Population-based Study BJU Int 2013; 111(1): 300-05. 